\title{
Analyzing the condition of Japanese electricity cost linkages by fossil fuel sources after the Fukushima disaster
}

\author{
Kentaka Aruga ${ }^{1}$ iD \\ Received: 10 October 2019 / Accepted: 5 March 2020 / Published online: 14 March 2020 \\ (C) The Author(s) 2020
}

\begin{abstract}
This study analyzes the dynamics of the linkages among costs of electricity generation via crude oil, natural gas, and coal for the periods before and after the Fukushima accident. We find that Markov regime switching in the cost spreads between the fossil fuels has become more frequent after the Fukushima accident. Johansen and Bierens-Martins cointegration tests also indicate that since the accident, the oil and gas relationship has become more evident, while the cost relationships between coal and other fossil fuels have weakened. These results might reflect changes in Japanese energy policy since the accident to promote LNG and compensate for the reduced energy supply from closing the nuclear power plants, while concurrently coping to meet the requirements of the Paris Agreement to reduce $\mathrm{CO}_{2}$ emissions.
\end{abstract}

Keywords Fukushima accident $\cdot$ Energy mix $\cdot$ Fossil fuel cost linkage $\cdot$ Structural change

JEL Classification C32 $\cdot \mathrm{Q} 02 \cdot \mathrm{Q} 40$

\section{Introduction}

The Great East Japan Earthquake, the largest earthquake ever recorded in Japan [1], occurred in March 2011. The earthquake triggered a massive tsunami, and the Fukushima Daiichi Nuclear Power Plant (FDNPP) suffered enormous damage from the tidal wave. After the plant was hit by the tsunami, the plant lost the entire electricity source used to cool down its reactor, leading to a nuclear meltdown.

This accident motivated Japan to transform its nuclearreliant energy policy into one less dependent on nuclear power. Before the Fukushima disaster, nearly $30 \%$ of electricity in Japan was generated by nuclear power, but after the accident, nuclear power stations in Japan were gradually shut down. By May 2012, Japan had halted all of its nuclear power generation [2]. To compensate for the lost electricity from shuttering its nuclear power plants, Japan started to increase the use of fossil fuels after the disaster. In 2016, less than $2 \%$ of the electricity supplied in Japan was generated

Kentaka Aruga

kentaka.aruga@gmail.com

1 Graduate School of Humanities and Social Sciences, Saitama University, 255 Shimo-Okubo, Sakura-ku, Saitama 338-8570, Japan from nuclear power [3], and the electricity shortage due to stopping nuclear power generation has been mostly filled by increased generation from burning crude oil, natural gas, and coal.

Figure 1 shows the recent shares of total electricity generation in Japan by source. Comparing the percentages of electricity generated from crude oil, natural gas, and coal before and after 2011 indicates that all the shares of these three major fossil fuel sources expanded between 2010 and 2012. The dramatic increase in the combined share of natural gas and coal after the Fukushima disaster is especially discernible from Fig. 1, and this heightened share persisted into 2016. Meanwhile, although dependency on crude oil increased immediately after 2011, Fig. 1 also shows that by 2014, the share of oil had declined back to the level from before the Fukushima accident.

These changes in the energy mix for electricity generation after the Fukushima disaster likely have disturbed the linkages among the costs of electricity from various fuel sources. Many studies have investigated how the Japanese energy mix should change [4-6] or have analyzed Japanese people's preferences regarding energy mixes after the disaster [7, 8]. However, until now, few studies have used quantitative methods to analyze how electricity prices or 


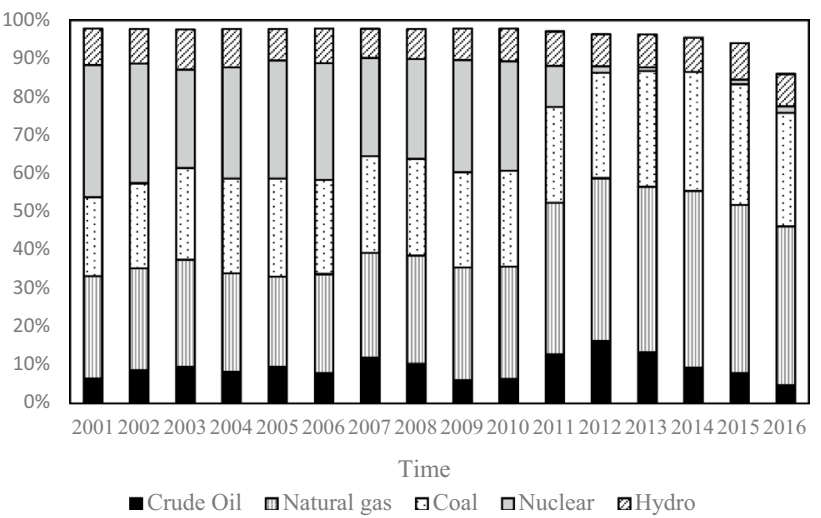

Fig. 1 Share of Japanese electricity generation by source Source: FEPC [3]

costs of electricity generation from various fuel sources have changed since the Fukushima disaster.

To fill this knowledge gap, the objective of this study is to examine the dynamics of the linkages among the costs of electricity generation from crude oil, natural gas, and coal before and after the Fukushima accident. We expect if the Fukushima accident influenced the fluctuations in the relationships among the three fossil fuel costs, the cost spreads between the fossil fuels are likely to be fluctuated differently before and after the accident. This is investigated with Markov regime switching model (MRSM). Furthermore, we conjecture that if the accident affected the cost linkages, the cointegration relationship (i.e., a systematic co-movement) between the costs would have changed before and after the accident. ${ }^{1}$ We verify this with the Johansen [11] and Bierens-Martins [12] time-varying cointegration tests.

The study investigates the changes in the dynamics of linkages among the costs of electricity generation by fossil fuels based on the market efficiency hypothesis [9]. This hypothesis states that all available information such as effects from the economies of scale and changes in import prices are reflected in the fuel costs if the markets are informationally efficient.

We believe that this investigation is a valuable case study for understanding how phasing out nuclear power influences the linkages among the costs of variously sourced electricity generation. Uncovering such linkages is important because linked energy markets can be used for hedging price and cost risks. This research improves our understanding of how cost linkages can be affected by energy shocks like the

\footnotetext{
1 A cointegration relationship is sustained between variables when a linear combination of nonstationary variables is stationary, which indicates that the test variables move together during the test period [10].
}

Fukushima accident. The study is one of the first studies to examine the structural changes in fossil fuel costs that occurred after the nuclear stations were shut down. Hence, this study is not only valuable for a country like Japan striving to implement effective policies to reduce its dependence on nuclear power, but also it provides valuable information for other countries that are phasing out nuclear power and need to meet their electricity demand by substituting with other energy sources.

In addition, recently, many studies investigating market linkages among different energy sources began to consider effects of structural breaks in their time series data [13-15], but up until now, no studies have applied both the MRSM and time-varying cointegration methods for identifying market linkages. The MRSM captures a more complex dynamic pattern of a time series data using an unobserved switching variable assuming the structural change is unobserved, and the time-varying cointegration method incorporates the gradual change in the cointegration relationship when testing market linkages among different energy sources. Hence, our study considers both unobserved and gradual structural changes when analyzing energy market linkages and it is a useful reference for performing a sophisticated analysis for investigating the dynamics of energy market linkages.

In the next section, we review the literature related to this study. In the third section, we explain the methods of the study, and the fourth section discusses the results of the quantitative analyses. Finally, the fifth section concludes the paper.

\section{Related literature}

This section reviews the relevant literature, including studies investigating shocks on energy policies due to the Fukushima accident and those identifying market linkages among energy commodities.

In one study investigating shocks on energy policies due to the Fukushima disaster, Joskow and Parsons [16] analyzed how the Fukushima accident affected subsequent nuclear energy policies in other countries such as the US, the UK, and China. A paper by Hayashi and Hughes [5] is more directly related to our study since they examined how the Fukushima accident has influenced the short- and longterm energy policies implemented in Japan to maintain its energy security. They explained that the Japanese government expectedly would increase the use of fossil fuels for electricity because at the moment, it still would be difficult for Japan to replace nuclear power with renewable energy. Vivoda [17] also studied the consequences of the Fukushima disaster for Japanese energy policy and argued that in the short to medium term, the shares of imported oil, coal, and liquefied natural gas (LNG) would expand to compensate 
for the reduction in nuclear power generation after the Fukushima accident.

Various studies have investigated market linkages among energy commodities, but since our study focuses on crude oil, natural gas and coal markets, here we only cover studies that have examined market linkages among these three fossil fuels. Batten et al. [18] tested the causality relationships between crude oil and NYMEX Henry Hub Natural Gas futures prices for the 1994 to 2014 period and provided evidence that the relationship between crude oil and gas was not stable during the period investigated. Brigida [19] also used the NYMEX, natural gas, and oil prices but for the 1997:6-2012:9 period to capture the cointegration relationship between these markets. Additionally, he applied the MRSM to analyze the switching relationship between natural gas and oil prices and found that these markets did not permanently decouple in the early 2000s and that there was a temporary shift in regimes. Finally, Bachmeier and Griffin [20] analyzed market integration in the US crude oil, coal, and natural gas markets using daily price data and showed that coal-gas and coal-oil markets have only been very superficially linked; whereas, oil-gas did exhibit some evidence of market integration.

None of the above-mentioned studies have investigated the effects of structural change on energy market linkages by applying the MRSM and time-varying cointegration method to capture both cases when the change in the time series is unobserved and gradual. One of the contributions of the present study to existing literature is in this way of examining the effects of structural change on energy market linkages. The other contribution is that this study is a valuable case study for understanding what could happen when a country phase out from nuclear power and how it will affect the market linkages among the fossil fuel energy sources.

\section{Methods}

The effects of the Fukushima accident on the electricity cost relationships among crude oil, natural gas, and coal are analyzed with the Markov regime switching model (MRSM) and cointegration tests.

\section{Markov regime switching model}

We use the MRSM to analyze the dynamics of the spreads among the costs of electricity generated from crude oil, natural gas and coal. Then, we compare the regimes (states) identified through the MRSM with the date of the Fukushima accident and analyze whether the duration and turning points of the regimes captured by the MRSM are related to the Fukushima accident.
We apply the MRSM to the rate of change (ROC) of the $\log$ cost ratio for pairings of crude oil-, natural gas-, and coal-based electricity. Let $Y_{t}$ be the ROC of the log cost ratio between two of the three fossil fuel costs investigated in this study at time $t$. That is, $Y_{t}=100 \cdot\left(\ln C_{t}-\ln C_{t-1}\right) / \ln C_{t-1}$, where $C_{t}$ and $C_{t-1}$ are the cost ratios between two of the three fossil fuel costs at time $t$ and time $t-1$. Such ROC cost ratio series are used because the MRSM requires the sample data used in the model to be stationary [21].

The MRSM in this study has the following form:

$Y_{t}=\mu_{S_{t}}+\varepsilon_{t}$,

where $\mu_{S_{t}}$ is a regime switching intercept in an unobserved state $S_{t}$, and $\varepsilon_{t}$ is a random variable that is identically and independently distributed. Denoting $k$ as the number of unobserved states, the Markov switching variable $S_{t}$ is a first-order Markov chain with the following transition probability matrix:

$\mathrm{P}=\left(\begin{array}{cccc}P_{11} & P_{12} & \cdots & P_{1 k} \\ P_{21} & P_{22} & \cdots & P_{2 k} \\ \vdots & \vdots & \cdots & \vdots \\ P_{k 1} & P_{k 2} & \cdots & P_{k k}\end{array}\right)$,

where $P_{i j}=\operatorname{Pr}\left(S_{t}=j \mid S_{t-1}=i\right)$ and $\sum_{j=1}^{k} P_{i j}=1$ for $\forall i$. Hence, $P_{i j}$ is the probability of moving from state $i$ at time $t-1$ to state $j$ at time $t$. We set the number of states to two based on the Schwarz [22] and Hannan-Quinn criteria [23].

In the two-state MRSM, the coefficients and the transition probability matrix are estimated with the maximum likelihood function:

$\mathrm{L}(\theta)=\sum_{t=1}^{T} f\left(y_{t} \mid \Omega_{t-1} ; \theta\right)$,

where $f\left(y_{t}\right)$ is the probability density function of $y_{t}, T$ is the last observation period, $\Omega_{t-1}$ is the matrix capturing available information at time $t-1$, and $\theta=\left(\mu_{1}, \mu_{2} ; \sigma_{1}, \sigma_{2}\right)$ is the vector of parameters. ${ }^{2}$ Once $\theta$ and the transition probability matrix are estimated, the regime probabilities $\operatorname{Pr}\left(S_{t}=j \mid \Omega_{\mathrm{T}} ; \theta\right)$ of being in state $j$ can be calculated based on knowledge of the complete series. Our study uses these regime probabilities, often called smoothed probabilities [24]. We plot these smoothed probabilities over our sample period and compare the probabilities before and after March 11, the date of the Fukushima accident.

We also estimate the constant expected duration [25] $E(D)$, which is the length of time that the sample data are

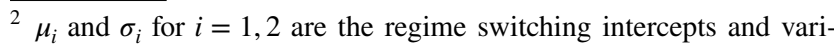
ances of the model presented in Eq. (1).
} 
expected to stay in state $j$ based on the transition probabilities. $E(D)$, can be expressed as follows:

$$
E(D)=\frac{1}{1-P_{j j}} .
$$

\section{Cointegration tests}

We perform the cointegration tests on the cost linkages between pairings of the oil, natural gas, and coal sample series. For this purpose, we execute the Johansen [11] and Bierens-Martins (BM) [12] tests. We initially test the fossil fuel costs for their cointegration relationships using the Johansen test because the BM test requires the test series to be cointegrated. Thus, we apply the BM test only if we identify cointegration relationships based on the Johansen test. The BM test is useful for examining the time-varying cointegration relationships between variables. Since the objective of this study is to discover whether cost relationships among the fossil fuels used for electricity changed before and after the Fukushima accident, we conduct the cointegration tests for three time periods: the whole sample period, the period before March 2011, and the period after March 2011.

Before performing the Johansen test, we execute the augmented Dickey-Fuller (ADF), Phillips-Perron (PP), and Kwiatkowski-Phillips-Schmidt-Shin (KPSS) stationarity tests on the three fossil fuel costs. To consider the effects of structural breaks in the stationarity tests, we also apply the innovational outlier (IO) unit root test [26]. The IO unit root test evaluates the validity of the stationarity tests in the presence of a break that occurs gradually following a dynamic path similar to innovations. Taking $T_{\mathrm{b}}$ as the time when a structural change in the trend function occurs, we use the following regression model for the IO unit root test:

$C_{t}=\mu+\theta D U_{t}+\delta D_{t}\left(T_{\mathrm{b}}\right)+\alpha C_{t-1}+\sum_{i=1}^{k} c_{i} \Delta C_{t-i}+e_{t}$,

where $\mu$ is an intercept term, $C_{t}$ is the fossil fuel cost of interest, $D U_{t}$ is an intercept break variable taking 1 when $\mathrm{t}>T_{\mathrm{b}}$ and 0 otherwise, and $D_{t}\left(T_{\mathrm{b}}\right)=1$ when $t=T_{\mathrm{b}}$ and 0 otherwise. This model only allows a change in the intercept, and we identify the break date when this change occurs by minimizing the $t$-statistic for the intercept break coefficient. We select the optimal number of lags to include in the test equation according to the Schwarz information criteria. We apply the above-mentioned stationarity tests to the whole sample period and to the samples before and after March 2011.

After we identify the order of integration for the cost series according to the result of the unit root tests, we perform the Johansen cointegration test on the three major fossil fuel costs.
We implement the Johansen test based on the following vector error correction model (VECM) of order $p$ :

$\Delta C_{t}=\Pi C_{t-1}+\sum_{i=1}^{p-1} \Gamma_{i} \Delta C_{t-i}+\varepsilon_{t}, \quad t=1, \ldots, T$,

where $C_{t} \in \mathbb{R}^{k}$ is the vector of $k$ cost series, $\varepsilon_{t} \sim$ i.i.d. $N_{k}(0, \Omega)$, and $T$ is the number of observations. $\Pi=\alpha \beta^{\prime}$, where $\alpha$ and $\beta$ are both fixed $k \times r$ matrices with $r$ cointegrating ranks. Both $\Pi$ and $\Gamma_{i}$ are $k \times k$ fixed matrices and $1 \leq r<k$. We estimate the following trace and maximum eigenvalue test statistics with the maximum likelihood function in the Johansen test:

$\lambda_{\text {trace }}(r)=-T \log \left(1-\hat{\lambda}_{i}\right)$,

$\lambda_{\text {Max }}(r, r+1)=-T \log \left(1-\hat{\lambda}_{r+1}\right)$,

where $\hat{\lambda}_{i}$ is the $i$ th largest eigenvalue of $\Pi$ matrix. Following Bierens and Martins [12], we identify the lag order of the Johansen cointegration model by the Schwarz and Hannan-Quinn information criteria. Using these statistics, we verify the order of cointegration among the fossil fuel costs.

Besides the simple Johansen test, we also apply the recursive cointegration technique on the data based on the trace statistic presented in Eq. (7). In this recursive analysis, the trace statistic is initially estimated over an initial sample, and as additional observations are added to the sample data, this statistic is re-estimated recursively at each iteration. This recursive estimation continues until it covers the full sample period. Then, the result of the test statistics is plotted and evaluated graphically. In our study, the recursive trace statistics are scaled to unity by their $5 \%$ critical values and the critical values larger than unity in the figure indicate cointegration relationships.

Finally, if the Johansen test suggests that the cost series are cointegrated, we conduct the BM test on the series. The $\mathrm{BM}$ test is different from the Johansen test by assuming that the VECM shown in Eq. (6) is a time-varying VECM. In the $\mathrm{BM}$ test, the $\beta$ of the Johansen test is defined as a new cointegrating vector $\beta_{t}$. Bierens and Martins [12] specify the cointegrating vector by a finite sum of Chebyshev time polynomials $p_{i, T}(t)$ such that:

$$
\begin{gathered}
p_{0, T}(t)=1, p_{i, T}(t)=\sqrt{2} \cos \left(\frac{i \pi(t-0.5)}{T}\right), \\
t=1,2, \ldots, T, \quad \text { and } \quad i=1,2,3, \ldots
\end{gathered}
$$

Then, $\beta_{t}$ can be written as

$\beta_{t}=\beta_{m}\left(\frac{t}{T}\right)=\sum_{i=0}^{m} \xi_{i, T} p_{i, T}(t)$ 
Table 1 Summary statistics (yen/kWh)

\begin{tabular}{|c|c|c|c|c|c|c|c|}
\hline & Mean & Maximum & Minimum & Std. dev. & Skewness & Kurtosis & Obs \\
\hline \multicolumn{8}{|c|}{ Entire period (2001:1-2018:8) } \\
\hline Crude oil & 23.52 & 37.30 & 16.62 & 4.54 & 0.43 & 2.55 & 212 \\
\hline Natural gas & 9.92 & 16.09 & 6.89 & 2.31 & 0.70 & 2.59 & 212 \\
\hline Coal & 11.42 & 15.81 & 9.61 & 1.16 & 1.23 & 4.36 & 212 \\
\hline \multicolumn{8}{|c|}{ Before the accident $(2001: 1-2011: 2)$} \\
\hline Crude oil & 21.99 & 37.30 & 16.62 & 4.47 & 1.04 & 3.97 & 122 \\
\hline Natural gas & 8.69 & 13.92 & 6.89 & 1.55 & 1.16 & 4.15 & 122 \\
\hline Coal & 10.93 & 13.94 & 9.61 & 0.84 & 1.27 & 5.09 & 122 \\
\hline \multicolumn{8}{|c|}{ After the accident (2011:3-2018:8) } \\
\hline Crude oil & 25.60 & 32.34 & 18.22 & 3.77 & 0.03 & 2.08 & 90 \\
\hline Natural gas & 11.59 & 16.09 & 7.70 & 2.13 & 0.20 & 2.11 & 90 \\
\hline Coal & 12.08 & 15.81 & 10.52 & 1.21 & 1.09 & 3.18 & 90 \\
\hline
\end{tabular}

where $\xi_{i, T} p_{i, T}=1 / T \sum_{t=1}^{T} \beta_{t} p_{i, T}(t)$ for $i=0, \ldots, T-1$, and $m$ is the maximum order of Chebyshev polynomials. This assumption that $\beta_{t}$ changes gradually over time is different from Hansen [26], which considers the structural change in the VECM as a sudden change.

Substituting $\Pi=\alpha \beta_{t}^{\prime}=\alpha\left(\sum_{i=0}^{m} \xi_{i, T} p_{i, T}(t)\right)^{\prime}$ into Eq. (6), the time-varying VECM can be presented as

$\Delta C_{t}=\alpha\left(\sum_{i=0}^{m} \xi_{i, T} p_{i, T}(t)\right)^{\prime} C_{t-1}+\sum_{i=1}^{p-1} \Gamma_{i} \Delta C_{t-i}+\varepsilon_{t}, \quad t=1, \ldots, T$.

This equation can be rewritten as

$\Delta C_{t}=\alpha \xi^{\prime} C_{t-1}^{m}+\sum_{i=1}^{p-1} \Gamma_{i} \Delta C_{t-i}+\varepsilon_{t}$

where $\xi^{\prime}=\left(\xi_{0}^{\prime}, \xi_{1}^{\prime}, \ldots, \xi_{m}^{\prime}\right)$, is an $r \times(m+1) k$ matrix of rank r. $C_{t-1}^{m}$ is defined as

$C_{t-1}^{m}=\left(C_{t-1}^{\prime}, p_{1, T}(t) C_{t-1}^{\prime}, p_{2, T}(t) C_{t-1}^{\prime}, \ldots, p_{m, T}(t) C_{t-1}^{\prime}\right)$.

Using Eq. (12), we test the null hypothesis of time invariant cointegration such that $\xi^{\prime}=\left(\beta^{\prime}, O_{r, k . m}\right)$, meaning $\xi^{\prime} C_{t-1}^{m}=\beta^{\prime} C_{t-1}^{0}=\beta^{\prime} C_{t-1}$, against the alternative hypothesis of time-varying cointegration. Finally, we set the order of $m$ in the BM test to four, which is similar to previous studies [28-30].

The data for the costs of electricity generation from crude oil, natural gas, and coal are from pps-net.org, a site managed by the General Incorporated Association of Energy Information Center in Japan. The costs are estimated by the Working Group for Verifying the Power Generation Cost under the Agency for Natural Resources and Energy of Ministry of Economy, Trade and Industry, Japan, by considering various fuels involved in running the power plants such as the depreciation rate and legal duration period of power plants, $\mathrm{CO}_{2}$ price, fuel cost, nuclear fuel cycle cost and so on
[31]. We use the monthly data for the 2001:1-2018:8 period. The unit of the cost series used in this study is in yen per kilowatt hour $(\mathrm{kWh})$. For the analysis purposes, we used the natural logarithm of the costs.

Table 1 reports the summary statistics of the cost series used in the study. The summary statistics indicate that the mean fossil fuel costs all became higher after the Fukushima accident. This outcome suggests that electricity costs by crude oil and natural gas became higher in Japan after the accident due to increased fossil fuel imports [17]. Hence, it is believable that the electricity costs by fossil fuels increased accordingly. Table 1 also indicates that the standard deviations for natural gas and coal increased after the accident, while that for crude oil decreased. This outcome implies that, compared to the crude oil cost, natural gas and coal costs became more volatile after the accident.

\section{Results and discussion}

To analyze the fluctuations in the cost spreads among crude oil, natural gas, and coal before and after the Fukushima accident, we apply the MRSM to the ROC of the cost ratios among the three fossil fuels. Figure 2 shows the results of the smoothed regime probabilities identified by the MRSM for the ROC of the cost ratios. ROC Ln(oil/gas), ROC $\mathrm{Ln}$ (oil/coal), and ROC Ln(coal/gas) in Fig. 2 denote the ROC of the log cost ratios between oil and gas, oil and coal, and coal and gas, respectively. Comparing the regime probabilities for the period before and after the Fukushima accident, Fig. 2 shows that, in all three cost ratios, regime 1 captures sudden shocks in the fossil fuel cost ratio. Meanwhile, regime 2 captures stable states from before the global financial crisis of 2008 and the Fukushima disaster. Notably, according to all three cost ratios, switching from one regime to another has become more frequent since the Fukushima accident. Intriguingly, for the oil-gas and coal-gas cost 
Fig. 2 Markov switching smoothed regime probabilities
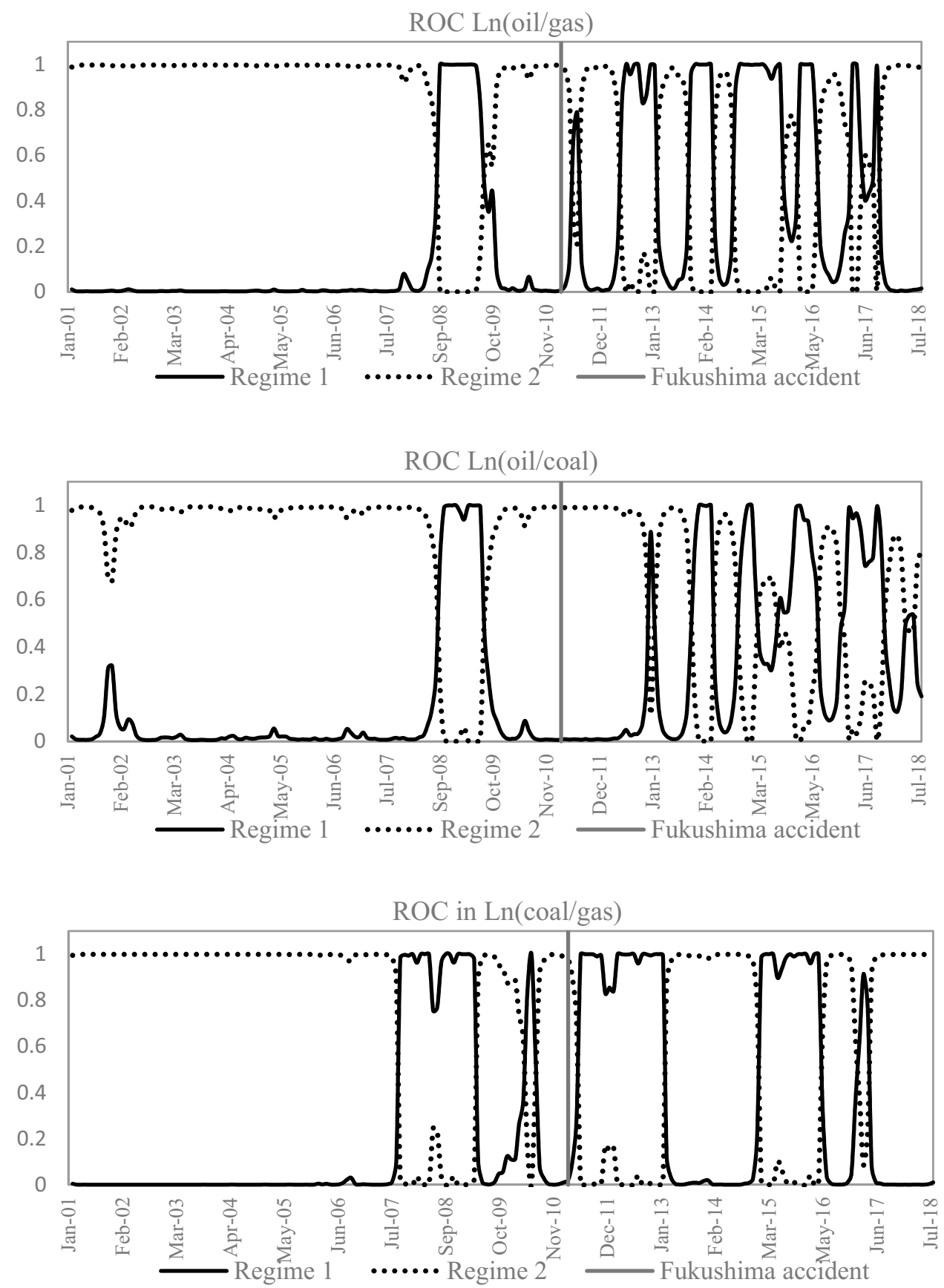

ratios, the regime switching becomes observable right after March 2011; whereas, the regime switching only becomes apparent in late 2012 for the ROC of the oil-coal ratio.

To reveal the dates of changes for the two regimes in the ROC of the cost ratio series and compare them with the date of the Fukushima accident, Table 2 illustrates the dates when the switching starts and ends. ${ }^{3}$ It is similar

\footnotetext{
3 The starting and ending dates in Table 2 only display the turning points based on the 0.5 regime probability threshold, but as shown in Fig. 2, the actual regime changes become apparent in March 2011
}

to Table II of Hamilton [24], but Table 2 of our study also shows the expected duration for the two regimes. The results in Table 2 suggest that after the Fukushima disaster, the regime switching has become more frequent and the cost spreads between the fuel costs have become unstable. The results also indicate that expected durations

Footnote 3 (continued)

for the ROC of the oil-gas and coal-gas cost ratios, which is a little earlier than these starting and ending dates. 
Table 2 Regime classification and its expected duration

\begin{tabular}{|c|c|c|c|c|c|c|c|c|c|}
\hline \multirow[t]{2}{*}{ Regime } & \multicolumn{3}{|c|}{ ROC Ln (oil/gas) } & \multicolumn{3}{|c|}{ ROC Ln (oil/coal) } & \multicolumn{3}{|c|}{ ROC Ln(coal/gas) } \\
\hline & Start & End & $\begin{array}{l}\text { Expected } \\
\text { duration }\end{array}$ & Start & End & $\begin{array}{l}\text { Expected } \\
\text { duration }\end{array}$ & Start & End & $\begin{array}{l}\text { Expected } \\
\text { duration }\end{array}$ \\
\hline \multirow[t]{8}{*}{ Regime 1} & Sep-08 & Aug-09 & 6.57 & Sep-08 & Aug-09 & 6.01 & Oct-07 & May-09 & 9.99 \\
\hline & Jun-11 & Aug-11 & & Jan-13 & Feb-13 & & May-10 & Aug-10 & \\
\hline & Jun-12 & Mar-13 & & Dec-13 & Мay-14 & & Jun-11 & Mar-13 & \\
\hline & Nov-13 & May-14 & & Nov-14 & Apr-15 & & Feb-15 & May-16 & \\
\hline & Oct-14 & Oct-15 & & Sep-15 & Jul-16 & & Feb-17 & May-17 & \\
\hline & Feb-16 & Jul-16 & & Jan-17 & Nov-17 & & & & \\
\hline & Mar-17 & Jun-17 & & Мay-18 & Jul-18 & & & & \\
\hline & Sep-17 & Oct-17 & & & & & & & \\
\hline \multirow[t]{9}{*}{ Regime 2} & Feb-01 & Sep-08 & 19.20 & Feb-01 & Sep-08 & 19.92 & Feb-01 & Oct-07 & 26.13 \\
\hline & Aug-09 & Jun-11 & & Aug-09 & Jan-13 & & Мay-09 & May-10 & \\
\hline & Aug-11 & Jun-12 & & Feb-13 & Dec-13 & & Aug-10 & Jun-11 & \\
\hline & Mar-13 & Nov-13 & & Мay-14 & Nov-14 & & Mar-13 & Feb-15 & \\
\hline & May-14 & Oct-14 & & Apr-15 & Sep-15 & & Маy-16 & Feb-17 & \\
\hline & Oct-15 & Feb-16 & & Jul-16 & Jan-17 & & Мay-17 & na & \\
\hline & Jul-16 & Mar-17 & & Nov-17 & May-18 & & & & \\
\hline & Jun-17 & Sep-17 & & Jul-18 & na & & & & \\
\hline & Oct-17 & na & & & & & & & \\
\hline
\end{tabular}

Start represents the date when regime probabilities start to exceed 0.5 and end is the date when probabilities turn below 0.5

\begin{tabular}{|c|c|c|c|c|c|c|c|c|c|}
\hline & \multicolumn{3}{|c|}{ ROC Ln(oil/gas) } & \multicolumn{3}{|c|}{ ROC Ln(oil/coal) } & \multicolumn{3}{|c|}{ ROC Ln(coal/gas) } \\
\hline & Coeff & $z$-stat & Prob & Coeff & $z$-stat & Prob & Coeff & z-stat & Prob \\
\hline$\mu_{1}$ & 0.86 & 0.43 & 0.66 & -0.76 & -0.43 & 0.67 & 3.53 & 0.33 & 0.74 \\
\hline$\mu_{2}$ & 0.09 & 0.23 & 0.67 & $0.57 *$ & 1.76 & 0.08 & -01.10 & -01.42 & 0.16 \\
\hline $\log \sigma_{1}$ & $2.66^{* * * *}$ & 24.87 & 0.00 & $2.47 * * *$ & 18.14 & 0.00 & $4.41 * * *$ & 45.54 & 0.00 \\
\hline $\log \sigma_{2}$ & $0.93 * * *$ & 0.07 & 0.00 & $1.25 * * *$ & 14.79 & 0.00 & $2.16 * * *$ & 28.36 & 0.00 \\
\hline
\end{tabular}

*** and * denote significance at $1 \%$ and $10 \%$, respectively. The estimation is performed on the 2001:12018:8 period
Table 3 Markov switching model estimation
The following discusses the results of the cointegration tests. We conduct the stationarity tests on the three fossil fuel cost series prior to performing the cointegration tests. Table 4 shows the results of these tests. These results indicate that the PP and IO unit root tests provide evidence that all three fossil fuel costs are integrated at order one. This result is consistent in all three time periods. Hence, we further test the cointegration relationships among the series.

Table 5 depicts the results of the Johansen test. The results indicate that all the binary cointegration relationships have been impacted since the Fukushima accident. The results in Table 5 also suggest that although the cointegration relationships are sustained in all cost linkages before the accident, coal has lost its relationships with oil and gas since the accident. On the other hand, the robustness of the statistical significance for the oil and gas relationship has 
Table 4 Unit root tests

\begin{tabular}{|c|c|c|c|c|c|c|c|c|}
\hline & \multicolumn{4}{|l|}{ Level } & \multicolumn{4}{|c|}{ First differences } \\
\hline & $\mathrm{ADF}$ & $\mathrm{PP}$ & KPSS & IO & $\mathrm{ADF}$ & PP & KPSS & IO \\
\hline \multicolumn{9}{|c|}{ Entire period (2001:1-2018:8) } \\
\hline Crude oil & $-3.346^{*}$ & -2.610 & $0.267 * * *$ & -2.997 & $-7.620 * * *$ & $-9.145^{* * *}$ & 0.027 & $-9.781 * * *$ \\
\hline Natural gas & -2.660 & -2.136 & $0.208 * *$ & -1.895 & $-6.708 * * *$ & $-8.404 * * *$ & 0.047 & $-8.313 * * *$ \\
\hline Coal & -2.600 & -2.759 & $0.114 *$ & -1.777 & $-7.073 * * *$ & \#\#\#\#\#*** & 0.040 & $-7.327 * * *$ \\
\hline \multicolumn{9}{|c|}{ Before the accident (2001:1-2011:2) } \\
\hline Crude oil & -2.486 & -2.325 & $0.181 * *$ & -2.366 & $-6.199 * * *$ & $-4.318 * * *$ & 0.042 & $-6.374 * * *$ \\
\hline Natural gas & -2.558 & -2.348 & $0.122 *$ & -1.489 & $-4.826^{* * *}$ & $-7.294 * * *$ & 0.052 & $-7.519 * * *$ \\
\hline Coal & -2.327 & -2.084 & $0.131 *$ & -1.190 & $-7.486^{* * *}$ & $-7.486 * * *$ & 0.054 & $-8.198 * * *$ \\
\hline \multicolumn{9}{|c|}{ After the accident (2011:3-2018:8) } \\
\hline Crude oil & -2.702 & -2.352 & $0.144^{*}$ & -3.846 & $-7.668^{* * *}$ & $-7.031 * * *$ & 0.080 & $-7.010 * * *$ \\
\hline Natural gas & -2.382 & -2.050 & $0.181 * *$ & -3.762 & $-4.770 * * *$ & $-4.871 * * *$ & $\begin{array}{l}0.134 \\
*\end{array}$ & $-4.862 * * *$ \\
\hline Coal & $-3.300^{*}$ & -2.319 & $0.137 *$ & -1.614 & $-5.131 * * *$ & $-8.199 * * *$ & 0.039 & $-9.551 * * *$ \\
\hline
\end{tabular}

$\mathrm{ADF}, \mathrm{PP}$, and KPSS unit root tests include both constant and trend, and IO unit root test only includes a constant

$* * *, * *$, and $*$ denotes significance at $1 \%, 5 \%$, and $10 \%$, respectively

Table 5 Johansen tests

\begin{tabular}{lcccl}
\hline Variables & $H_{0}:$ rank $=r$ & Trace test & Max test & Lag length \\
\hline Entire period (2001:1-2018:8) & & & \\
Oil and gas & $r=0$ & $43.565^{* * *}$ & $39.366^{* * *}$ & 2 \\
& $r \leq 1$ & 4.198 & 4.198 & \\
Oil and coal & $r=0$ & 13.839 & 9.119 & 2 \\
& $r \leq 1$ & 4.720 & 4.720 & \\
Coal and gas & $r=0$ & 8.851 & 5.593 & 2 \\
& $r \leq 1$ & 3.259 & 3.259 & \\
Before the accident $(2001: 1-2011: 2)$ & & \\
Oil and gas & $r=0$ & $19.555^{*}$ & $15.866^{*}$ & 4 \\
& $r \leq 1$ & 3.689 & 3.689 & \\
Oil and coal & $r=0$ & $21.961 * *$ & $17.015 * *$ & 2 \\
& $r \leq 1$ & 4.946 & 4.946 & \\
Coal and gas & $r=0$ & $20.378^{* *}$ & $16.728^{* *}$ & 2 \\
& $r \leq 1$ & 3.650 & 3.650 & \\
After the accident $(2011: 3-2018: 8)$ & & \\
Oil and gas & $r=0$ & $30.960^{* * *}$ & $28.582^{* * *}$ & 2 \\
& $r \leq 1$ & 2.378 & 2.378 & \\
Oil and coal & $r=0$ & 7.962 & 6.070 & 1 \\
& $r \leq 1$ & 1.892 & 1.892 & \\
Coal and gas & $r=0$ & 8.130 & 7.257 & 2 \\
& $r \leq 1$ & 0.873 & 0.873 & \\
\hline
\end{tabular}

$* * *, * *$, and $*$ denote significance at $1 \%, 5 \%$, and $10 \%$, respectively. The optimal lag length is identified by the BIC and HQ criteria

increased from the $10 \%$ level before the accident to the $1 \%$ level after. This result suggests that the cointegration relationship between the oil and gas costs has become more evident since the accident. These results might imply that as the oil-gas cost relationship has strengthened after the accident; this change has interrupted the post-Fukushima coal-oil and coal-gas cost relationships, leading coal to lose its linkages with other fossil fuels.

The difference in the cointegration relationships between oil-gas versus oil-coal and coal-gas can be also detected from the results of the recursive cointegration test. For the period before the 2008 financial crisis, all three fossil fuel costs do not have cointegrating relationships, but since 2008, oil and gas costs have become cointegrated (Fig. 3). In particular, comparing the trace statistics for periods before and after the Fukushima accident, Fig. 3 shows a large gap in the values of the trace statistics between oil-gas versus oil-coal and coal-gas. These results also indicate that the oil-gas linkage has become stronger compared to the coal-oil and coal-gas linkages since the accident.

Finally, we perform the BM time-varying cointegration test on the cost series based on the results of the Johansen test. Table 6 shows that the null hypothesis of time-invariant cointegration is rejected for oil-gas in the entire period case, as well as for oil-gas and oil-coal for the period before the Fukushima accident. This result reveals that the cointegration relationship between oil and gas costs has fluctuated during the whole sample period, meaning that the cointegration relationship between these costs has been unstable throughout the investigated period. The results of the oil-gas and oil-coal cost relationships for the period before the accident also indicate that for the period before the accident, their cointegration relationships have been time-variant. In contrast, the results also suggest that the cointegration relationships for coal-gas for the period before the accident and oil-gas for the period after the accident have been time-invariant. The time-invariant 
Fig. 3 Recursive plots of Johansen's trace statistic. Trace statistics above unity imply rejection of the null hypothesis of rank zero, suggesting that the two series are cointegrated $(r=1)$

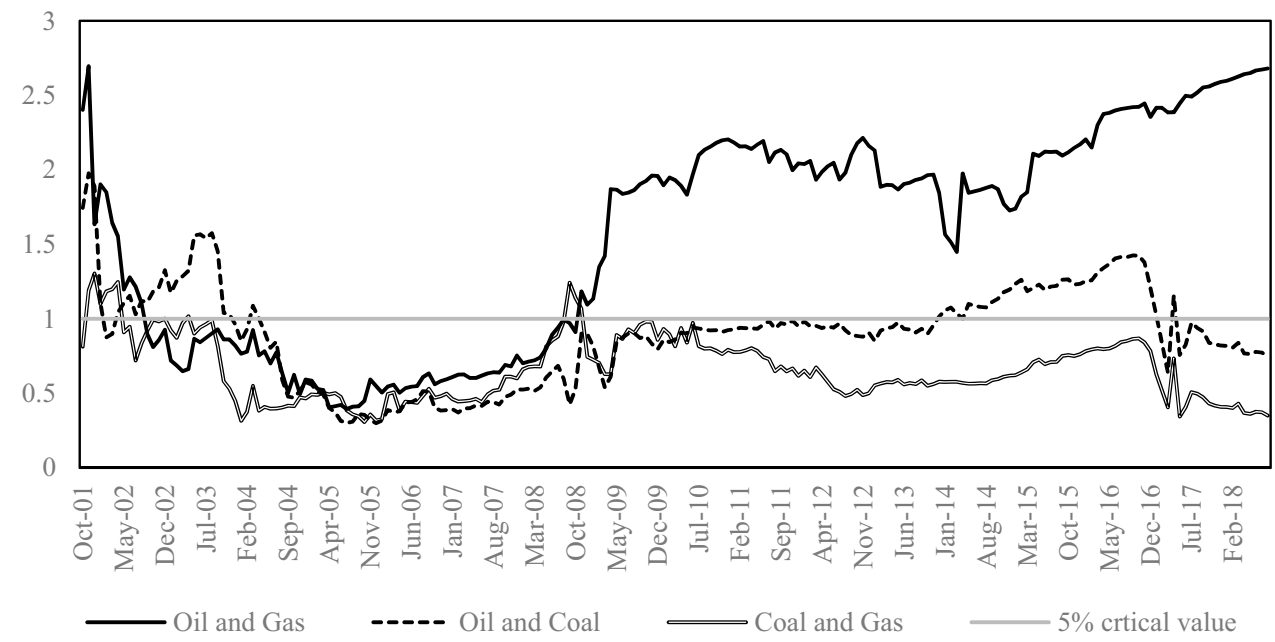

Table 6 Bierens-Martins tests

\begin{tabular}{|c|c|c|c|}
\hline Variables & $\begin{array}{l}\text { Chebyshev time } \\
\text { polynomials }\end{array}$ & Test statistic & $P$ value \\
\hline \multicolumn{4}{|c|}{ Entire period (2001:1-2018:8) } \\
\hline \multirow[t]{3}{*}{ Oil and gas } & $m=1$ & $6.51 * *$ & 0.039 \\
\hline & $m=2$ & $16.06 * * *$ & 0.003 \\
\hline & $m=4$ & $43.42 * * *$ & 0.000 \\
\hline \multicolumn{4}{|c|}{ Before the accident (2001:1-2011:2) } \\
\hline \multirow[t]{3}{*}{ Oil and gas } & $m=1$ & $7.93 * *$ & 0.019 \\
\hline & $m=2$ & $24.53 * * *$ & 0.000 \\
\hline & $m=4$ & $37.81 * * *$ & 0.000 \\
\hline \multirow[t]{3}{*}{ Oil and coal } & $m=1$ & $12.49 * * *$ & 0.002 \\
\hline & $m=2$ & $25.96 * * *$ & 0.000 \\
\hline & $m=4$ & $32.08 * * *$ & 0.000 \\
\hline \multirow[t]{3}{*}{ Coal and gas } & $m=1$ & 3.10 & 0.212 \\
\hline & $m=2$ & 5.68 & 0.224 \\
\hline & $m=4$ & $14.12 * *$ & 0.028 \\
\hline \multicolumn{4}{|c|}{ After the accident (2011:3-2018:8) } \\
\hline \multirow[t]{3}{*}{ Oil and gas } & $m=1$ & 1.47 & 0.481 \\
\hline & $m=2$ & $13.54 * * *$ & 0.009 \\
\hline & $m=4$ & $13.57 * *$ & 0.035 \\
\hline
\end{tabular}

$* * *$ and $* *$ denote significance at $1 \%$ and $5 \%$, respectively

cointegration relationship for oil-gas for the period after the accident probably signifies that the oil-gas cointegration relationship has become more persistent since the accident.

\section{Conclusions}

The study investigated how shutting down the nuclear power plants in Japan after the Fukushima accident has affected the dynamics of the linkages among the costs of electricity generation from crude oil, natural gas, and coal.
First, we found from the MRSM that the Markov regime switching in the cost spreads between the fossil fuels has become more frequent for the period after the Fukushima accident. Undoubtedly, the accident has altered the dynamics of the fossil fuel cost relationships. This result suggests that a flexible energy policy would be more effective than a fixed energy policy after the Fukushima accident to adjust the policy to frequent fluctuations in the fossil fuel cost linkages.

Second, we learned from the cointegration tests that cost linkages between oil-gas, oil-coal, and coal-gas have all been affected by the Fukushima accident. The cointegration tests indicated that the cost relationship between oil and gas became stronger and more persistent while coal lost its linkages with other fossil fuel costs. This result might reflect the change in Japanese energy policy after the accident to promote using more LNG to compensate for the reduced energy supply from closing nuclear stations, while also coping to meet the requirements of the Paris Agreement to reduce $\mathrm{CO}_{2}$ emissions. The cointegration relationship between oil and gas costs is compatible with Bachmeier and Griffin [16] identifying a price linkage for oil and gas prices, so the result might suggest that the Japanese oil and gas markets have become more dependent on the global oil and gas markets since the Fukushima accident.

Overall, the study revealed the usefulness of applying both the MRSM and time-varying cointegration method to understand how events like the Fukushima disaster have influence on linkages among the energy source markets. However, it is likely that the results of the application are not always as clear as this study and more applications need to be done to find out how effective the method is when investigating the dynamics of linkages among the energy markets.

Although the present study investigated the effects of shutting down the nuclear plants on the fossil fuel markets, the methods applied in this study is also useful for analyzing how building new nuclear power plants will impact the fossil 
fuel markets of a certain country. Recently, to reduce its reliance on fossil fuels, even an oil-rich country like United Arab Emirates (UAE) is constructing its first nuclear power plant and other Middle East and North Africa (MENA) region countries like Qatar, Syria, Tunisia and Sudan are showing interests on developing nuclear power plants [32]. We believe the methods developed in this study would be helpful for understanding how the linkages among the fossil fuel markets in countries could be affected from a change in energy mix after introducing nuclear power.

Acknowledgements This work was supported by JSPS KAKENHI Grant nos. JP25712025 and JP18K12763.

Open Access This article is licensed under a Creative Commons Attribution 4.0 International License, which permits use, sharing, adaptation, distribution and reproduction in any medium or format, as long as you give appropriate credit to the original author(s) and the source, provide a link to the Creative Commons licence, and indicate if changes were made. The images or other third party material in this article are included in the article's Creative Commons licence, unless indicated otherwise in a credit line to the material. If material is not included in the article's Creative Commons licence and your intended use is not permitted by statutory regulation or exceeds the permitted use, you will need to obtain permission directly from the copyright holder. To view a copy of this licence, visit http://creativecommons.org/licenses/by/4.0/.

\section{References}

1. Bhattacharya, S., Hyodo, M., Goda, K., Tazoh, T., Taylor, C.A.: Liquefaction of soil in the Tokyo Bay area from the 2011 Tohoku (Japan) earthquake. Soil Dyn. Earthq. Eng. 31, 1618-1628 (2011)

2. Toudou, F.: Economical logics on restarting of nuclear power plants (in Japanese). J. Econ. (Niigata University) 96, 49-65 (2014)

3. The Federation of Electric Power Companies of Japan (FEPC): FEPC Infobase 2017. FEPC, Tokyo. http://www.fepc.or.jp/libra ry/data/infobase/. Accessed 4 Dec 2018 (2017)

4. Huenteler, J., Schmidt, T.S., Kanie, N.: Japan's post-Fukushima challenge: implications from the German experience on renewable energy policy. Energy Policy 45, 6-11 (2012)

5. Hayashi, M., Hughes, L.: The policy responses to the Fukushima nuclear accident and their effect on Japanese energy security. Energy Policy 59, 86-101 (2013)

6. Hong, S., Bradshaw, C.J.A., Brook, B.W.: Evaluating options for the future energy mix of Japan after the Fukushima nuclear crisis. Energy Policy 56, 418-424 (2013)

7. Murakami, K., Ida, T., Tanaka, M., Friedman, L.: Consumers' willingness to pay for renewable and nuclear energy: a comparative analysis between the US and Japan. Energy Econ. 50, 178-189 (2015)

8. Rehdanz, K., Schroder, C., Nanita, D., Okubo, T.: Public preferences for alternative electricity mixes in post-Fukushima Japan. Energy Econ. 65, 262-270 (2017)

9. Fama, E.F.: Efficient capital markets: a review of theory and empirical work. J. Financ. 25, 383-417 (1970)

10. Yu, E.S.H., Jin, J.C.: Cointegration tests of energy consumption, income, and employment. Resour. Energy Econ. 14, 259-266 (1992)
11. Johansen, S.: Estimation and hypothesis testing of cointegration vectors in gaussian vector autoregressive models. Econometrica 59, 1551-1580 (1991)

12. Bierens, H.J., Martins, L.F.: Time-varying cointegration. Econ. Theory 26(5), 1453-1490 (2010)

13. Lee, C.-C., Lee, J.-D.: Energy prices, multiple structural breaks, and efficient market hypothesis. Appl. Energy 86, 466-479 (2009)

14. Dogan, E.: Analyzing the linkage between renewable and nonrenewable energy consumption and economic growth by considering structural break in time-series data. Renew. Energy 99, 1126-1136 (2016)

15. Cabrera, B.L., Schulz, F.: Volatility linkages between energy and agricultural commodity prices. Energy Econ. 54, 190-203 (2016)

16. Joskow, P.L., Parsons, J.E.: The future of nuclear power after Fukushima. Econ. Energy Environ. Policy 1, 99-113 (2012)

17. Vivoda, V.: Japan's energy security predicament post-Fukushima. Energy Policy 46, 135-143 (2012)

18. Batten, J.A., Ciner, C., Lucey, B.M.: The dynamic linkages between crude oil and natural gas markets. Energy Econ. 62, 155-170 (2017)

19. Brigida, M.: The switching relationship between natural gas and crude oil price. Energy Econ. 43, 48-55 (2014)

20. Bachmeier, L.J., Griffin, J.M.: Testing for market integration crude oil, coal, and natural gas. Energy J. 27, 55-71 (2006)

21. Kuan, C.M.: Lecture on the Markov switching model. http:// homepage.ntu.edu.tw/ ckuan/pdf/Lec-Markov_note.pdf. Accessed 2 Feb 2019 (2002)

22. Schwarz, G.: Estimating the dimension of a model. Ann. Stat. 6 , 461-464 (1978)

23. Hannan, E.J., Quinn, B.G.: The determination of the order of an autoregression. J. R. Stat. Soc. B 41, 190-195 (1979)

24. Kim, C.J., Nelson, C.R.: State Space Models with Regime Switching: Classical and Gibbs Sampling Approaches with Applications. MIT Press, Cambridge (1999)

25. Hamilton, J.D.: A new approach to the economic analysis of nonstationary time series and the business cycle. Econometrica 57(2), 357-384 (1989)

26. Perron, P.: Further evidence on breaking trend functions in macroeconomic variables. J. Econ. 80(2), 355-385 (1997)

27. Hansen, P.R.: Structural changes in the cointegrated vector autoregressive model. J. Econ. 114, 261-295 (2003)

28. Lucey, B.M., Sharma, S.S., Vigne, S.A.: Gold and inflation(s) a time-varying relationship. Econ. Model. 67, 88-101 (2017)

29. Bilgin, M.H., Gogolin, F., Lau, M.C.K., Vigne, S.A.: Time-variation in the relationship between white precious metals and inflation: a cross-country analysis. J. Int. Financ. Mark. Inst. Money 56, 55-70 (2018)

30. Gogolin, F., Kearney, F., Lucey, B.M.: Uncovering long term relationships between oil prices and the economy: a time-varying cointegration analysis. Energy Econ. 76, 584-593 (2018)

31. Agency for Natural Resources and Energy, Ministry of Economy, Trade and Industry: Working Group for Verifying the Power Generation Cost. https://www.enecho.meti.go.jp/committee/council/ basic_policy_subcommittee/\#cost_wg. Accessed 20 Feb 2020 (2015)

32. Mahllooji, M., Gaudard, L., Ristic, B., Madani, K.: The importance of considering resource availability restrictions in energy planning: What is the footprint of electricity generation in the Middle East and North Africa (MENA)?" Sci. Total Environ. https ://doi.org/10.1016/j.scitotenv.2019.135035 (in press) 